\title{
Clinico-radiological Aspects of Neurocysticercosis in Pediatric Population in a Tertiary Hospital
}

\author{
Bandana Shrestha, 'Prabha Mainali, ${ }^{1}$ Sujan Sayami, ${ }^{1}$ Om Kumar Shrestha \\ 'Department of Pediatrics, ${ }^{2}$ Department of Radiology, Gandaki Medical college and Teaching Hospital, Pokhara, Nepal.
}

\section{ABSTRACT}

Introduction: Neurocysticercosisis common in developing countries including Nepal. Clinicalpresentations vary depending on the CT scan findings of head. Adequate information of neurocysticercosis in children from Western Nepal is lacking. This study was conducted with an objective of evaluating the most common clinical and radiological picture in children suffering from NCC at a tertiary care teaching hospital in Western Nepal.

Methods: Hospital records of all pediatric inpatients, admitted from $16^{\text {th }}$ June 2010 to $15^{\text {th }}$ December 2012, consistent with the diagnosis of Neurocysticercosis were reviewed.

Results: Forty nine cases of neurocysticercosis were enrolled. Their age varied 2.6 years to 14 years with the mean age of 10.6 years and the peak age was at 12 years with slight male predominance, ratio being male:female 1.2:1. The commonest presentation was seizures $(n=38 ; 77.5 \%)$; partial seizures being most common. Most of the lesions were single $(n=44 ; 89.8 \%)$, predominantly in the parietal region $(n=20 ; 40.8 \%)$ and most were in transitional stage $(61.22 \%)$ in Computed tomography (CT). However, number of lesions from CT scan of head showed no significance in association with seizure types $(p=0.84)$. In addition, perilesional edema and scolex within the lesion were noted in $67.34 \%$ and $18.36 \%$ of the cases respectively.

Conclusions: Any child presenting with acute onset of afebrile seizure should be screened for neurocysticercosis provided other common infective and metabolic causes are ruled out. CT scan is the valuable diagnostic tool to support our diagnosis.

Keywords: clinico-radiological profile; neurocysticercosis; pediatric population.

\section{INTRODUCTION}

Seedling of tissue-invading larvae (Cysticercus Cellulosae) of pork-tapeworm from intestine to the central nervous system results in neurocysticercosis (NCC). ${ }^{1} \mathrm{NCC}$ is widely prevalent in developing countries including Nepal. It is considered by World Health Organization to be the commonest preventable cause of epilepsy with an estimated 2 million people having epilepsy caused by Taenia solium infection. ${ }^{1}$
NCC is a major public health hazard causing substantial neurological morbidity and economic hardship. T. solium infection was reported upto $50 \%$ from Tanahun and Syangja districts populated by pig rearing farmers. ${ }^{2}$ There is a wide variation in the disease prevalence in different regions and different socio-economic groups across the country. ${ }^{1}$

Correspondence: Dr. Bandana Shrestha, Department of Pediatrics, Gandaki Medical and Teaching Hospital, Pokhara, Nepal. Email: bandana139@yahoo.com, Phone: 9846029000. 
This study was carried out with an objective of evaluating the most common clinical and radiological picture in children suffering from NCC at a tertiary care teaching hospital in Western Nepal. It also aims to identify the association between the seizure types and the number of lesions in neuroimaging.

\section{METHODS}

This is a hospital based retrospective study, carried out at a tertiary teaching hospital in Kaski district of Western Nepal from $16^{\text {th }}$ June 2010 to $15^{\text {th }}$ December 2012. A total of 49 children were included in the study that were diagnosed as NCC based on clinical and CT head findings. This study was conducted after taking ethical clearance from the Institute Ethical Review Board. The hospital records of all pediatric inpatients upto the age of 14 years who were admitted either through emergency department or through the pediatric outpatient department with the diagnosis of NCC were reviewed. Detail history was also traced from patient files from medical records and computed tomography (CT) scan reports from the Department of Radiology. The diagnosis was primarily based on clinical features of neurological involvement and CT scan of head consistent with neurocysticercosis, evidenced of cystic lesion showing the scolex, ring or disc enhancing lesion and multiple punctuate parenchymal brain calcification with or without contrast enhancement.

Number of lesions were counted in CT head and labelled as single or multiple (if two or more than two lesions in CT head). Further, disease activity was classified as active (appears on CT as hypodense cyst without enhancement), transitional (there is a ring or nodular contrast enhancement) and inactive (calcified lesion on CT) based on the viability of the parasite at the first CT. ${ }^{3,4}$

Complete blood count, Mantoux test and ESR were routinely done in all the patients to rule out tubercular infections of the brain, which may have CT findings mimicking NCC. Patients who presented with neurological manifestation but CT scan not showing the evidence of NCC and patients who presented with seizures but CT scan not done were excluded from the study. Data were entered using Microsoft excel and analyzed in SPSS version 10 using chi- square test. $P$ value of 0.05 was taken as cut off for statistical significance.

\section{RESULTS}

Out of total 217 admitted patients, presenting with either seizure or neurological deficit, 49 cases were diagnosed as NCC based on clinical and CT scan findings. There were slight male predominance; male:femaleratio was 1.22:1. The mean age of presentation was 10.6 years (ranged 2.6 to 14 years) with the peak age of diagnosis was at 12 years. Maximum number of the subjects werefound in the age group 11 to 14 year (28; $57.2 \%)$, youngest age at diagnosis was two years and sixmonths of age (Table1).

\begin{tabular}{|ccccc|}
\hline \multicolumn{5}{|c|}{ Table 1. Demographic profile of the study groups } \\
\hline Age (years) & Male & Female & Total & Percentage (\%) \\
$<2$ & 0 & 0 & 0 & 0 \\
$2-5$ & 2 & 1 & 3 & 6.12 \\
$6-10$ & 7 & 11 & 18 & 36.73 \\
$11-14$ & 18 & 10 & 28 & 57.14 \\
Total & 27 & 22 & 49 & 100 \\
\hline
\end{tabular}

Maximum number of patients were from Kaski district 14 (28.6\%) followed by 13 (26.5\%) Tanahun, 6 (12.3\%) Baglung, $4(8 \%)$ Parbat and Nawalparasi $(n=4 ; 8 \%)$ respectively ( Figure 1). Our findings show that most of the patients had mixed dietary habit. Majority of them (74\%) were non-vegetarian, in contrast to few (26\%) that claimed to have strict vegetarian diet.

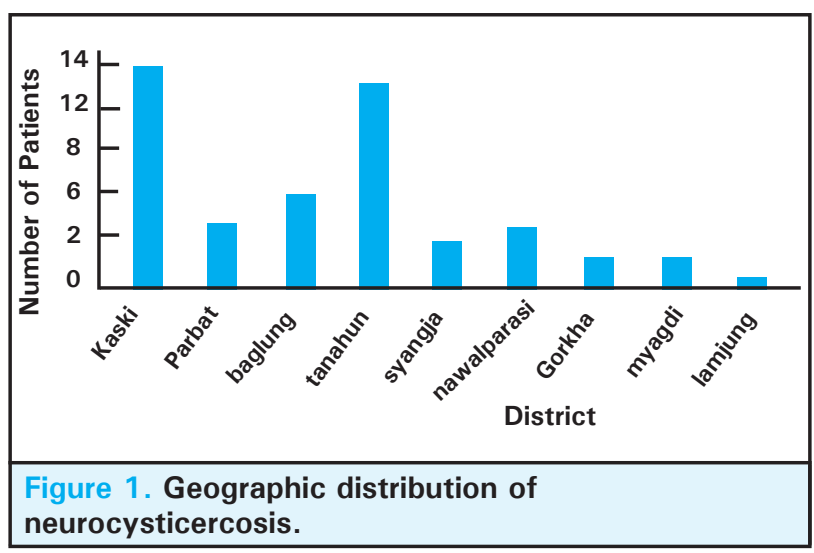

The most common presentation observed in this study was seizure, noted in 41 (83.67\%) children, predominately a partial seizure in $29(70.7 \%)$ cases compared to $12(29.3 \%)$ cases of generalized seizure. This was followed by sudden loss of consciousness in $19(38.77 \%)$ children, headache with or without vomiting in $14(28.6 \%)$ and dizziness in 4 (8.16\%) cases. Besides, hemiparesis/monoparesis, slurring of speech, loss of speech, behavior abnormalities were the other manifestations observed. Also of interest were observed cases in which one child presented with tingling sensation in right hand/arm and the other child with status epilepticus (Table 2). 
Shrestha et al. Clinico-radiological Aspects of Neurocysticercosis in Pediatric Population in a Tertiary Hospital

\begin{tabular}{|c|c|c|}
\hline Sign or symptoms & Total & Percentage(\%) \\
\hline $\begin{array}{l}\text { Seizure, } \\
\text { Partial } \\
\text { Generalised }\end{array}$ & $\begin{array}{l}41 \\
29 \\
12\end{array}$ & $\begin{array}{l}83.67 \\
70.7 \\
29.3\end{array}$ \\
\hline $\begin{array}{l}\text { Sudden loss of } \\
\text { consciousness }\end{array}$ & 19 & 38.77 \\
\hline $\begin{array}{l}\text { Headache / } \\
\text { Vomiting }\end{array}$ & 14 & 28.6 \\
\hline $\begin{array}{l}\text { Hemiparesis/ } \\
\text { Monoparesis }\end{array}$ & 2 & 4.1 \\
\hline $\begin{array}{l}\text { Slurring of speech/ } \\
\text { loss of speech }\end{array}$ & 2 & 4.1 \\
\hline Dizziness & 4 & 8.16 \\
\hline Others & 5 & 10.20 \\
\hline
\end{tabular}

In this study, CT scan of the head showed that 44 $(89.8 \%)$ patients had a single lesion whereas multiple lesions were noticed in $5(10.2 \%)$ patients. Approximate size of the lesion varied from $5 \mathrm{~mm}$ to $20 \mathrm{~mm}$, among which parietal region was the most common site of involvement, as were observed in 20 patients $(40.8 \%)$. Thirty $(61.22 \%)$ of the observed lesions in CT head were in transitional stage. This was followed by calcified granuloma and active stage that were noted in $17(34.7 \%)$ and $2(4.1 \%)$ of the cases respectively. Perilesional edema was seen in $33(67.3 \%)$ cases; of them, 28 cases were in degenerating (transitional) stage and the remaining 5 in calcified stage (Table 3 ).

\begin{tabular}{|c|c|c|c|}
\hline Lesions & haracteristics & $\begin{array}{l}\text { Total } \\
(\mathrm{n}=49)\end{array}$ & $\begin{array}{l}\text { Percentage } \\
(\%)\end{array}$ \\
\hline \multirow{2}{*}{ Number } & single & 44 & 89.8 \\
\hline & multiple & 5 & 10.2 \\
\hline \multirow{10}{*}{$\begin{array}{l}\text { Site } \\
\text { of the } \\
\text { lesion }\end{array}$} & Parietal & 20 & 40.8 \\
\hline & Frontal & 9 & 18.36 \\
\hline & Occipital & 3 & 6.12 \\
\hline & Temporal & 3 & 6.12 \\
\hline & Frontoparietal & 5 & 10.20 \\
\hline & Temporoparietal & 4 & 8.16 \\
\hline & Occipitoparietal & 4 & 8.16 \\
\hline & Occipitotemporal & 1 & 2.04 \\
\hline & $\begin{array}{l}\text { Lentiform } \\
\text { nucleus }\end{array}$ & 2 & 4.08 \\
\hline & Cerebellar & 1 & 2.04 \\
\hline
\end{tabular}

\begin{tabular}{|llll|}
\multirow{2}{*}{ Nature } & $\begin{array}{l}\text { perilesional } \\
\text { edema }\end{array}$ & 33 & 67.34 \\
& active & 2 & 4.1 \\
& transitional & 30 & 61.22 \\
& Calcified & 17 & 34.7 \\
\hline
\end{tabular}

Eccentric nodular hyper density representing scolex was found in $9(18.36 \%)$ of the cases. Routine investigation, which included complete blood count, Liver Function Test, Renal Function Test and ESR, were done in all cases and all were within the normal limits. Mantoux test was also done routinely in all cases and size of the induration was varied from 0 to $5 \mathrm{~mm}$.

\begin{tabular}{|c|c|c|c|}
\hline \multicolumn{4}{|c|}{$\begin{array}{l}\text { Table 4. Association between the type of seizure } \\
\text { and the number of lesion in CT scan. }\end{array}$} \\
\hline \multirow{2}{*}{$\begin{array}{l}\text { No. of lesion } \\
n \text { CT }\end{array}$} & \multicolumn{2}{|c|}{ Seizure type } & \multirow[t]{2}{*}{$\mathrm{p}$ value } \\
\hline & Partial & Generalised & \\
\hline Single & 26 & 11 & 0.8434 \\
\hline Multiple & 3 & 1 & \\
\hline Total & 29 & 12 & \\
\hline
\end{tabular}

\section{DISCUSSION}

Cysticercosis is a serious disease; with varied incubation period and multiple signs and symptoms. ${ }^{5}$ Infected people may remain asymptomatic for years. ${ }^{5}$ Although Cysticercosis infection is possible at any age, children are observed to be more vulnerable. Seizure is the most frequent presentation in both children and adults but are more frequent in children. ${ }^{6}$

Though there are very limited data on epidemiology of cysticercosis from Nepal, the available data suggest that the prevalence of taeniais in syangja and Tanahun were $43 \%$ and $18 \%$ respectively. ${ }^{7}$ Beside this, epilepsy in Nepal are increasing, with studies showing that up to 7.3 per 1,000 population may suffer from epilepsy, and almost $50 \%$ of the cases are due to neurocysticercosis. ${ }^{8}$ These days NCC seems to be increasing in frequency among the Nepalese population based on the data conducted in different hospitals in Kathmandu. ${ }^{8}$ This may rather reflect the more accurate diagnosis as a result of better knowledge of the biological cycle of Taeniasolium, improved understanding of the endemic poor environmental conditions, and the availability of precise neuro-radiological and immunological studies, however, the actual data on NCC in children not known.

As previously mentioned, commonly affected age in our study ranged from 11 to 14 years with the mean age being 10.6 years. This is comparable to other two studies which were conducted previously in the same area (western part of Nepal) where 
mean age of presentations were 10.8 years and 9.77 yearsrespectively. ${ }^{9,10}$ A study conducted by Shrestha BM in Lumbini Zonal Hospital showed affected age group ranged between 2 and 14 years with the mean age of 5.8 years and nearly $70 \%$ of children being older than 7 years. ${ }^{11}$ Another study conducted by Ruiz-Garcia in Mexico showed that mean age was 8 years of age. ${ }^{12}$ The reason why it is common in these age groups could be because of their tendency to intake outside food and poor hygiene.

In our study, the youngest patient to suffer from NCC is a girl, 2 years and 6 months of age. Our findings in terms of age groups associated with the disease are similar to those reported by Shrestha BM. ${ }^{11}$ However, one case had been reported in a patient below 2 years of age in a study conducted by Gauchan E. ${ }^{10}$ This reflects lower incidence of NCC in younger age groups (below 2 years of age) which could be because of the prolonged incubation period of T. Solium.

In our study, we observed slight male predominance compared to female ( $55 \%$ Vs $45 \%$ ). Similarly results of male outnumbering female have been shown in many other studies conducted previously. 6, 9,10,13-15 However, in contrast to these results, some studies have shown that girls are more affected compared to male. ${ }^{3,11,12}$ In fact, we believe that such sexual predilection should not have occurred and are purely coincidental.

As previously stated, the most common presentation of NCC is seizure. ${ }^{16-18}$ It is one of the major cause of epilepsy and accounts for as high as $50 \%$ of patients presenting partial seizure. ${ }^{19}$ Our study seems to be in accord to previous findings as we observed similar statistics in which seizure seems to be the most common manifestation (83.67\%). We also observed partial seizure to be more common as compared to generalized seizure (59.2\% Vs $29.3 \%)$. Similar results were noted in many other studies where seizure was shown to be the most common manifestation with predominant partial seizure. $6,9,11,12,14,20$ However, in contrast, generalized seizure has been noted to be predominant in a study conducted by Gauchan E et al. ${ }^{10}$

Raised ICP in the form of headache and vomiting is found to be $28.6 \%$ in the current study. This observation is supported by the data conducted in other studies where the incidence of raised ICP was found to $20.2 \%, 30 \%$, $38 \%$ respectively. ${ }^{6,9,11}$ Focal neurological deficit (like hemi/monoparesis), was observed in only $4.1 \%$ of cases in the present study which is comparable to the study conducted by Singhi et al . ${ }^{6}$

Diagnosis of the disease among affected individual rests mainly on neuroimaging. The $C T$ and MRI findings in parenchymalneurocysticercosis depend on the stage of development of the parasites. ${ }^{4,16}$ Though MRI may be a better tool to identify scolex, considering its lower cost and easy availability, CT scan remains the best investigation tool for confirming NCC in a poor country like Nepal. Parenchymal NCC, either single or multiple, is the most frequent form in children. ${ }^{12}$ Most of the lesions of CT head in our study was single (89.8\%). Similar findings were also seen in other studies where single lesions were found to be $76 \%, 81.6 \%, 83.7 \%$ respectively. ${ }^{6,10,11}$ In contrast, some other studies claimed that multiple lesions were predominant as compared to single lesions. ${ }^{9,12}$ In our study, association between seizure types and number of lesions in CT head $(p=0.84)$ seems very insignificant. However, this could be the result of a small sample size where the study was conducted.

In this study, we also observed that most common site of involvement is in the parietal lobe $(40.8 \%)$. Previous studies also revealed that parietal region is the most common site of involvement. ${ }^{9,10,14,21}$ Left parietal region is predominantly involved as compared to right parietal region $(70 \%$ vs. $30 \%)$ indicating that the dominant side of the brain is affected more. However, some previous studies have also claimed that right parietal lobe is more frequently involved compared to left parietal lobe. ${ }^{10}$.

The disease activity was classified as active, transitional and inactive, based on the viability of parasites at the first CT. ${ }^{3,4}$ Viable cyst lacks perilesional edema but the lesions may have an eccentric hyper dense nodule in their interior representing the scolex. ${ }^{4}$ The most common lesion in CT head in our study is of transitional type which was recorded in $30(61.22 \%)$ patients, whereas active lesion was the least and was recorded in only 2 (4.1\%) patients. Calcified lesion in CT head at the time of presentation was found in $17(34.7 \%)$ of the cases. Cerebral edema around the lesions in CT was noted in $33(67.34 \%)$ of the cases. Almost all perilesional edema were noted in transitional stage except in 5 cases where calcifications were accompanied by perifocal edema. This localized brain edema circumscribing ring enhancing/calcified lesions of NCC, can be considered to be the cause of seizures, which may be caused by an inflammatory response to the liberation of antigens by the calcified cyst itself during its remodeling process. ${ }^{22}$

$\mathrm{MRI}$ is more sensitive in identifying the scolex within the cyst and detection of intraventricular and subarachnoid lesion whereas CT head is more sensitive in identifying calcified granuloma.4,16,18 Our study revealed scolex within the lesion in $18.36 \%$ of the cases. These lesions could have been found in higher frequency if MRI head were performed. Since CT head is easily accessible in our institute and is more cost effective as compared to MRI head, most children had undergone $\mathrm{CT}$ head to diagnose NCC. 
In our study, we have observed that the disease occurs more in Kaski district (28.6\%) followed by Tanahun $(26.53 \%)$ and Baglung (12.24\%). Previous studies conducted in the same western region of Nepal also revealed similar findings with the maximum cases of NCC being observed in Kaski district. ${ }^{10}$ Since our hospital is located in the central part of the Pokhara valley within Kaski district, which is considered to be the portal of entry to Western region of Nepal, this geographical convenience for people residing in the area might have been the reason for maximal disease distribution in Kaski region. People of all economic strata are inhabitated in Pokhara. So habit of eating outside food and unawareness of the personal habit could be the some of the reasons of its occurrence. Most of the households did not have a proper latrine or sewage disposal system and had a very low level of sanitary practice. This might be the reason for the transmission of the parasite in this geographic area.
Despite the amount of very useful statistics we were able to extract from this study, there did exist some limitations. Since it's a retrospective study, we were not able to review the details about patient's dietary habit such as pork-eating behavior and were also not able to inquire about pork farming in their household. In addition, we couldn't clearly differentiate generalized seizure from the partial seizure followed by secondary generalization.

\section{CONCLUSIONS}

Neurocysticercosis is one of the most common causes of epilepsy in pediatric population. Simple partial seizure is the most common mode of presentation and single parenchymal lesion with circumscribed cerebral edema with ring enhancement is the most common radiological feature of NCC. So, any child with acute onset of afebrile seizure should be screened for NCC provided other common causes been ruled out.

\section{REFERENCES}

1. Coyle CM, Mahanty S, Zunt JR, Wallin MT, Cantey PT, White JAC et al. Neurocysticercosis: neglected but not forgotten. [Online]. PlosNegl Trop Dis. [serial online] 2012 May [ cited 2013 Aug 8] 6(5):1-3 Available from:URL: http:/ / www.plosntds.org/

2. Rajshekhar V, Joshi DD, Doanh NQ, De NV, Xiaonong Z. Taenia solium taeniosis/cysticercosis in Asia:epidemiology, impact and issues. ActaTropica. 2003;87:53-60.

3. Ferreira LS, Zanardi VA, Scotono AE, Li LM, Guerreiro MM.Childhood epilepsy due to neurocysticercosis: a comparative study. Epilepsia. 2001;42(11):1438-44.

4. Garc1 H.H, Del Brutto O.H.Imaging findings in neurocysticercosis. Acta Tropica. 2003;87:71-8.

5. World Health Organization. Taeniasis/ cysticercosis. [online]. 2013 Feb. Available from:

6. URL :http://www.who.int/mediacentre/factsheets/fs376/ en/index.html

7. Singhi P, Ray M, Singhi S, Khandelwal N.Clinical spectrum of 500 children with neurocysticercosis and response to albendazole therapy. J child Neurol. 2000;15(4):207-13.

8. Joshi DD, Maharjan M, Johnson MV , Willingham AL, Gaihr Y, Sharma M. Taeniasis/cysticercosis situation in Nepal. Southeast Asian J Trop Med Public Health.2004;35(suppl 1):252-7.
9. Joshi DD, Bista PR, Ito A, Yamasaki H.Present situation of porcine taeniasis and human cysticercosis in Nepal. Southeast Asian J Trop Med Public Health. 2007;38 Suppl 8:144-50.

10. Basu S, Ramchandran U, Thapliyal A.Clinical profile and outcome of pediatric neurocysticercosis: A study from western Nepal. Pediatr Neurol. 2007;5:45-52.

11. Gauchan E, Malla T, Basnet S, Rao KS.Variability of presentations and CT-scan findings in children with neurocysticercosis. Kathmandu Univ Med J. 2011;9,34(2):17-21.

12. Shrestha BM.Childhood Neurocysticercosis: clinico-radiological profile and outcome. J Nepal Paediatr Society. 2008;28(1):14-6.

13. Ruiz-García M, González-Astiazarán A, Rueda-Franco F. Neurocysticercosis in children,clinical experience in 122 patients. Child's Nerv Syst.1997;13: 608-12.

14. Morales NM, Agapejev S, Morales RR et al. Clinical aspects of neurocysticercosis in children. Pediatric Neurology. 2000;22:287- 91

15. Singhi PD, Dinakaran J, Khandelwal N, Singhi SC. One vs. Two years of anti-epileptic therapy in children with single small enhancing CT lesions. J Trop Pediatr. 2003;49(5):274-8. 
16. Kashyap B, Das S, Jain S,Agarwal A, Kaushik JS, Kaur IR. Correlation between the clinico radiological heterogeneity and the immune-inflammatory profiles in pediatric patients with neurocysticercosis from a tertiary referral centre.J Trop Pediatr. 2012;58(4):320-23.

17. Singhi P, Singhi S. Neurocysticercosis in children. J Child Neurol. 2004;19: 482-92.

18. Blanton R. Cysticercosis. In: Behrman RE, Kliegman RM, Jenson HB,editors. Nelson Text Book of Pediatrics. $19^{\text {th }}$ ed. Philadelphia: Saunders; 2004. p. 1234-37.

19. Singhi P, Singh S.Neurocysticercosis in children. Indian J Pediatr. 2009 May;76:537-45.
20. Mishra N, Belbase M, Shrestha D, Poudel R, Mishra P.Childhood neurological illness in Nepal. J Nepal Health Res Counc. 2010 Apr;8(16):55-62.

21. Singhi P. Corticosteroids versus albendazole for treatment of single small enhancing computed tomographic lesions in children with neurocysticercosis. J Child Neurol. 2004;19:323-27.

22. Balaji J, Meikandan D.Clinical and radiological profile of neurocysticercosis in south Indian children. Indian J Pediatr. 2011Aug;78(8):1019-20.

23. Antoniuk SA, Bruck I, Santos LCD ,Pintarelli VL, Navolar FBB .Seizures associated with calcifications and edema in neurocysticercosis. Pediatr Neurol. 2001;25:309-11. 